\title{
ANÁLISE DO CONTEÚDO DE 'SAÚDE' EM LIVROS DIDÁTICOS
}

\author{
Adriana M ohr*
}

Resumo: 0 artigo propõe critérios para análise e discute o conteúdo de saúde presente em livros didáticos para o ensino fundamental. Exemplifica-se a utilização de tais critérios na análise de três coleções de livros didáticos de 1 a a 4 a séries.

Unitermos: Educação em saúde; livros didáticos; ensino de ciências, educação fundamental.

Abstract: The article proposes a set of criteria to be adopted in the analysis of textbooks used by students from the four initial years of elementary school in Brazil. The health notions identified in three collections are here analysed.

Keywords: H ealth education; textbooks; science education; primary education.

\section{Introdução}

0 texto que se segue foi extraído (com modificações) da dissertação de mestrado apresentada em 1994 ao Curso de Mestrado em Educação do Instituto de Estudos Avançados em Educação (Fundação G etúlio Vargas, Rio de Janeiro). Ele constitui o núcleo principal inédito daquele trabalho, que teve como objetivo analisar o conceito de saúde veiculado em livros didáticos do ensino fundamental. Apesar de sua importância, mas por causa da sua extensão, ele foi retirado do artigo A Saúde na Escola: análise de livros didáticos de 1a a 4a série. (M ohr, 1995). Sugere-se consultar esse artigo para uma complementação da presente leitura. N aquele artigo aborda-se resumidamente a finalidade dos programas de saúde escolares e a problemática do livro didático na escola; descreve-se o material utilizado na pesquisa e os métodos para análise dos livros didáticos; discute-se em função dos resultados encontrados (que são os dados apresentados no presente texto) o conceito de saúde veiculado pelas obras analisadas e se apresenta conclusões e sugestões.

0 motivo da publicação do texto que se segue deve-se à importância que atribuo ao detalhamento pormenorizado e explícito do material submetido aos critérios de análise propostos quando se efetua um trabalho de análise do livro didático. D esta forma o próprio trabalho de análise pode ser, também, julgado e analisado pelo leitor. Via de regra (e meu artigo citado anteriormente não foi exceção), dispomos de bibliografia que apresenta conclusões sobre as análises realizadas mas não apresenta o material analisado que permitiu aquelas conclusões. Além da necessária transparência dos dados com os quais se trabaIha nas análises de livros didáticos, tenho certeza de que somente uma indicação precisa dos pontos problemáticos pode permitir ao autor, professores do ensino fundamental que procedem análises de livros didáticos e outros profissionais envolvidos na questão, um conjunto

* Professora Assistente do D epartamento de M etodologia de Ensino da U niversidade Federal de Santa Catarina (email: amohr@matrix.com.br). 
de dados realmente úteis para sua reflexão e análise independentes. E com tal propósito que tal texto foi originalmente escrito e presentemente publicado.

0 conteúdo do presente texto foi apresentado durante o "Encontro de Pesquisadores em Educação para a Saúde - abordagem de temas de saúde no livro didático", realizado na Faculdade de Ciências, U N ESP, em Bauru, de 20 a 21 de agosto de 1999, especialmente na sessão que teve a participação dos professores das redes de ensino de Bauru e região. As discussões que se seguiram demonstram a necessi dade de se continuar realizando trabalhos que tenham por objetivo analisar o livro didático, bem como o potencial que 0 tema tem como gerador de questionamentos da própria prática docente.

0 s resultados que seguem resultaram da aplicação de critérios elaborados com a finalidade de anali sar o conceito de saúde presente e veiculado nos livros didáticos. 0 s conteúdos relativos à 'saúde' foram identificados tanto nos capítulos dedicados especialmente ao tema, quanto naqueles relativos a ciências. 0 s livros didáticos analisados foram dos autores Bellucci e Cavalcante (1991), M arote (1991) e Passos et al. (1991).

Ao contrário do que ocorreu no texto da dissertação, neste artigo optou-se pela organização dos dados a partir dos critérios de análise e não por coleções de livros didáticos.

\section{Critérios de análise}

Foram propostos critérios de análise que pudessem revelar como a saúde é tratada nos livros didáticos. 0 s critérios foram organizados de modo a constituir uma ficha (figura 1 ) que expressou o resumo esquemático da análise de cada volume.

O s critérios ${ }^{1}$ elaborados e as respectivas avaliações possíveis foram os seguintes:

Para cada conteúdo apresentado no livro didático identifiquei, em primeiro lugar, a presença ou ausência de conceituação ou definição. 'Conceito' é utilizado em sua significação mais ampla de idéia ou noção geral acerca de algo. Assim, quando se fala de conceituação no livro didático, entende-se que o texto deva apresentar informações e explicações desenvolvidas de tal modo que permitam ao aluno a compreensão ou concepção geral (ainda que pouco precisa e não formalizada) sobre 0 assunto em questão. A 'definição', por sua vez, é mais formal, mais rígida. Para definir há que ser preciso: é necessário delimitar o objeto da definição à sua forma mais individual e restrita. Para a conceituação, a presença da definição não é condição sine qua non; o que é geralmente falso na situação inversa: sem a conceituação, nem sempre é possível compreender uma definição. Q uando explícitos, CON CEITOS E DEFIN IÇÕ ES podem aparecer no início ou no fim da exposição do tema. Se implícitos, o texto deve fornecer elementos para sua formulação pelo próprio aluno. $Q$ uando inexistentes na forma explícita ou pobres em subsídios para a formulação pelo aluno, considerei como ausente.

Principal mente por serem de livros destinados aos primeiros anos escolares, o texto deve ser claro, explicativo eacessível. Logo, éfundamental a avaliação da qualidade no DESEN VOLVIMENTO DOS CONCEITOS E DEFINIÇÕES e da EXPLICAÇÃO DOS TERM OS DESC O N HECID OS (geralmente técnicos) introduzidos. A adequação do vocabulário

\footnotetext{
${ }^{1} 0$ s critérios estão grafados em maiúsculas e as possíveis avaliações atribuídas a cada um deles estão em negrito.
} 
Título do livro:

Série

CONTEÚDO

\begin{tabular}{|c|c|}
\hline Conceitos e definições & $\begin{array}{l}\text { explícito preliminar } \\
\text { explícito posterior } \\
\text { implícito } \\
\text { ausente } \\
\end{array}$ \\
\hline $\begin{array}{l}\text { D esenvolvimento dos } \\
\text { conceitos e definições }\end{array}$ & $\begin{array}{l}\text { bom } \\
\text { aceitável } \\
\text { insuficiente } \\
\text { inaceitável } \\
\end{array}$ \\
\hline $\begin{array}{l}\text { Explicação dos termos } \\
\text { desconhecidos }\end{array}$ & $\begin{array}{l}\text { sim } \\
\text { não } \\
\text { inexistentes } \\
\text { estão presentes }\end{array}$ \\
\hline Prérequisitos & $\begin{array}{l}\text { parcialmente } \\
\text { ausentes } \\
\text { desnecessários }\end{array}$ \\
\hline Correção científica & $\begin{array}{l}\text { boa } \\
\text { aceitável } \\
\text { incorreta }\end{array}$ \\
\hline $\begin{array}{l}\text { A dequação à idade } \\
\text { mínima }\end{array}$ & $\begin{array}{l}\text { sim } \\
\text { em parte } \\
\text { não }\end{array}$ \\
\hline $\begin{array}{l}\text { A dequação à realidade } \\
\text { econômica }\end{array}$ & $\begin{array}{l}\text { sim } \\
\text { em parte } \\
\text { não }\end{array}$ \\
\hline $\begin{array}{l}\text { A dequação à realidade } \\
\text { geográfica }\end{array}$ & $\begin{array}{l}\text { sim } \\
\text { em parte } \\
\text { não } \\
\end{array}$ \\
\hline Enfoque sanitário & $\begin{array}{l}\text { preventivo } \\
\text { curativo }\end{array}$ \\
\hline $\begin{array}{l}\text { Ações requeridas/ } \\
\text { recomendadas }\end{array}$ & $\begin{array}{l}\text { individuais } \\
\text { coletivas }\end{array}$ \\
\hline $\begin{array}{l}\text { Influência/relação com } \\
\text { meio ambiente }\end{array}$ & $\begin{array}{l}\text { sim } \\
\text { em parte } \\
\text { não }\end{array}$ \\
\hline $\begin{array}{l}\text { Aprofundamento } \\
\text { relativo à série anterior }\end{array}$ & $\begin{array}{ll}\text { sim } \\
\text { nãó } \\
\end{array}$ \\
\hline $\begin{array}{l}\text { Tipo de atividades } \\
\text { propostas }\end{array}$ & $\begin{array}{l}\text { análise } \\
\text { resol. problemas } \\
\text { cópia do texto } \\
\text { ativid. extra-livro } \\
\text { resposta aberta } \\
\text { inexistente } \\
\end{array}$ \\
\hline $\begin{array}{l}\text { Forma de execuçãa das } \\
\text { atividades propostas }\end{array}$ & $\begin{array}{l}\text { individual } \\
\text { grupo } \\
\end{array}$ \\
\hline |lustração & $\begin{array}{l}\frac{\text { correta }}{\text { aceitável }} \\
\text { incorreta } \\
\text { inexistente }\end{array}$ \\
\hline
\end{tabular}

explícito preliminar

explícito posterior

ausente

bom

nsuficiente

inexistentes

desnecessários

aceitável

incorreta

em parte

em parte

em parte

năo

individuais

coletivas

em parte

não

não

ativid. extra-livro

resposta aberta

\section{Figura 1 - ficha de análise dos livros didáticos}

Autor

Editora: Ano: página

Editora: Ano: página 
não-técnico foi desconsiderada na análise, por ultrapassar os objetivos propostos, embora reconheça sua capital importância para a inteligibilidade de qualquer texto escrito.

PRÉ-REQUISITOS podem ser necessários para a compreensão do texto ou ser, ainda, desnecessários. No primeiro caso, considerei-os presentes quando encontrados no mesmo volume ou em volume anterior da coleção. Q uando não suficientemente adequados, foram classificados como parcialmente presentes.

A condição de tornar acessível ao aluno um dado conteúdo não deve, nem precisa, ser feita com o sacrifício de sua CORREÇÃO CIENT ÍFICA. N este item identifiquei a propriedade e atualidade dos textos, conceitos e definições.

A aprendizagem é mais eficiente à medida que os conteúdos e sua forma de apresentação se identificam com situações e experiências vividas pelo aluno. D esta forma, considerei importante verificar se os conteúdos adaptam-se à diversidade de REALID ADES ECO N ÔM ICAS e GEO GRÁFICAS. Alguns dos títulos constantes do M anual de Escolha do Livro D idático (M EC/PN LD) têm especificação regional. O s livros analisados foram distribuídos no Estado do Rio de Janeiro.

Fundamental, também, é examinar os conteúdos quanto à ADEQUAÇ̃̃O À ID ADE M I N IM A dos alunos aos quais os livros se destinam. Embora não tenha realizado uma análise, como requer um trabalho com objetivo específico de avaliar a adequação do conteúdo ao desenvolvimento cognitivo dos alunos, a comparação de alguns conteúdos pôde detectar certas incongruências.

As AÇÕES REQ UERID AS E RECO M EN D AD AS, por sua vez, podem levar em conta tanto os comportamentos individuais como aqueles de caráter coletivo.

Considerando-se que a saúde e a doença não são entidades independentes, estáticas, mas influenciadas e condicionadas por fatores do AM BIEN TE, é de fundamental importância que a abordagem dos programas de saúde tenha um enfoque ecológico, inserindo 0 homem como parte de um ecossistema.

É importante a análise relativa ao APRO FU N D AM EN TO dos conteúdos apresentados e habilidades desenvolvidas em relação ao apresentado no volume anterior, uma vez que os temas principais podem ser recorrentes em todos os volumes de uma coleção.

É desejável que as ATIVID ADES PRO POSTAS contemplem a aquisição de conhecimentos, a capacidade de análise, de crítica e estimulem a iniciativa dos alunos. Essas atividades constituem um fator decisivo para avaliação da qualidade do livro didático. D esta forma, identifiquei os tipos de atividades propostas em cinco categorias. Classificadas como análise estão aquelas que demandam formação de um conceito ou compreensão do texto. Resolução de problemas caracteriza atividades onde 0 autor sugere uma situação para a qual o aluno deve propor soluções. Cópia corresponde ao nível de questões literais e literais transformadas de Anderson (1972) (citado por M olina, 1987) que implica a identificação visual de elementos do texto, respectivamente em sua forma literal e ligei ramente transformada. As atividades extra-livro são aquelas que não se prendem ao livro didático. Resposta aberta caracteriza a atividade na qual 0 aluno deve expressar uma opinião ou relatar comportamentos e experiências. Foi identificada a FORMA DE EXECUÇÃO DAS ATIVIDADES PROPOSTAS, se individual ou para realização em grupo. 
Por fim, a qualidade, a correção ea adequada inserção das ILUST RAÇ O ES no texto são fatores importantes para a compreensão dos conteúdos apresentados. Além disso, elas podem constituir um componente importante nos custos de produção do livro.

\section{Análise dos livros didáticos através dos critérios propostos}

\section{Conceitos, definições e seu respectivo desenvolvimento.}

\section{- Coleção Integrando 0 aprender (IA)}

A falta de conceituação dos assuntos componentes dos Programas de Saúde, assim como seu desenvolvimento, na maioria das vezes insuficiente ou inaceitável do ponto de vista da correção científica, constituem-se num dos principais problemas e falhas da coleção IA. Assim, a nutrição, constante de todos os volumes como título de capítulo, não é, em nenhum momento, conceituada ou definida explicitamente, nem são fornecidos os elementos para que o aluno elabore seu próprio conceito do que seja a nutrição. 0 que os autores desenvolvem sob o título de nutrição refere-se a um de seus componentes, a alimentação, apresentada unicamente sob o ponto de vista da ingestão de alimentos. A falta de conceituação e desenvolvimento das idéias é evidente, também, no tema saúde, nos volumes de 1a $2^{a}$ e e $4^{a}$ séries. N este caso, não existe texto ou atividade de síntese para que o aluno possa compreender a saúde como resultante das ações de alimentação, higiene e ausência de doenças ou acidentes, apresentados separadamente dentro dos volumes. Somente no volume destinado à 3 a série (p. 267) encontramos a definição de saúde, feita de maneira explícita e incorreta porque negligencia o componente social constante da definição da O rganização Mundial de Saúde, que os autores citam de modo incompleto: Saúde é o bem-estar físico e mental das pessoas. Elementos necessários à conceituação de pre venção, agravos à saúde, doença ou lixo, idéias fundamentais em qualquer currículo de educação em saúde, estão também ausentes ao longo da coleção.

Principalmente se considerarmos que a coleção IA atinge alunos no início do contato formal com o conhecimento escolar, parece-me muito mais importante o desenvolvimento dos conceitos do que os enunciados das definições. $\mathrm{N}$ ão havendo a possi bilidade de formação de uma idéia geral, as definições transformam-se em meros exercícios de memorização: Vermin oses são doenças causadas por vermes que se instalam no intestino do homem ( 3 a série, p. 269), Ascaridíase é a doença causada por vermes chamados Ascaris lumbricoides ou simplesmente lombrigas. (4ạ série, p. 317), sem que seja possível a compreensão do fenômeno geral do parasitismo, nem do problema da verminose e suas implicações e relações com 0 organismo humano.

Contrastando com a pobreza na conceituação, no desenvolvimento e na explicação dos assuntos propostos, são abundantes as classificações, enumerações e apresentação de fatos estanques, reforçando a idéia de que o conhecimento nada mais é do que uma coleção de fatos. A classificação dos alimentos está presente em toda a coleção IA: de acordo com a origem nos volumes destinados à $1^{\underline{a}}$ e $2^{\underline{a}}$ séries e de acordo com a composição nos de $3^{a}$ e 4ạ . É exclusivamente morfológica e descritiva, na 4a série, a apresentação do aparelho digestivo humano (p. 307), quando nenhuma menção é feita à alimentação, tratada em 
separado nos capítulos de Programas de Saúde. D a mesma forma os agentes etiológicos são listados (4a série, p. 315). Semelhante tratamento é dispensado, em todos os volumes da coleção IA, ao saneamento básico, com a descrição sumária dos sistemas de tratamento de água e esgotos e a coleta do lixo.

0 fracionamento de assuntos complementares e interdependentes e a mera apresentação de fatos não seria tão grave, se houvesse proposta de integração e síntese dos conteúdos, antes ou após as análises particularizadas, o que não é o caso na coleção IA. 0 tema saúde, por exemplo, é dividido em cuidados com a alimentação, com a higiene, com o saneamento básico e com os agravos que pode sofrer. Estes assuntos são tratados de maneira estanque ao longo da coleção, como se as relações mútuas existentes entre eles não existissem. $\mathrm{N}$ em mesmo dentro dos subtemas a visão de conjunto sobressai. O s capítulos de agravos à saúde restringem-se a acidentes (na 1 a série) e a doenças contagiosas, que não incluem aquelas comuns na infância, e as verminoses (na $2^{2}$ e e $4^{a}$ série). No volume da 3 a série não há o capítulo agravos à saúde (ele é substituído pelas Verminoses). N ão há nenhuma menção na coleção sobre as doenças congênitas, hereditárias, crônico-degenerativas, envenenamento por medicamentos ou produtos domissanitários (neologismo utilizado na área de saúde para qualificar os produtos de limpeza, anti-sepsia, praguicidas, etc., de uso domiciliar) ou, ainda, sobre as diarréias infantis, todos eles assuntos que se referem a problemas e experiências da vida diária.

A falta de conceituação e o fracionamento dos temas propostos, somados à quantidade de informações de caráter prescritivo e receituário dos conteúdos de saúde, sem a devida conceituação, reduz os Programas de Saúde apresentados pela coleção IA em regras a serem seguidas. No volume de 1a série, 15 hábitos de higiene para ter boa saúde (p. 252), dez para evitar acidentes e conservar a saúde (p. 253), dois a respeito do lixo (p. 255); na 2a série, 12 para ter higiene e para cultivar bons hábitos al imentares (p. 251), 13 de higiene para ter boa saúde (p. 252), três para evitar as doenças contagiosas (p. 253), quatro para prevenir certas doenças (p. 254). No volume destinado à 3a série, 12 sobre os cuidados com a alimentação (p. 266), 19 sobre hábitos de higiene que ajudam a manter uma boa saúde (267), nove cuidados para evitar as verminoses (p. 271), 10 para evitar acidentes (p. 272). Finalmente, na $4^{\text {a }}$ série, nove sobre algumas regras de higi ene alimentar (p. 311), 11 para manter a saúde do nosso corpo e da nossa mente. [e] para viver bem em sociedade (p. 312) e sete para evitar as verminoses (p. 317). 0 impressionante, além do número que atinge a soma de 136, é que tais recomendações não são explicadas. Bem fundamentadas, até que seriam importantes na formação dos conhecimentos e comportamentos do indivíduo com relação à sua saúde. Assim, comer carnes sempre bem cozidas (3a , p. 271), lavar as mãos antes das refe ç̧ões, após usar 0 sanitário e ao chegar da rua (2aㅡ, p. 252), escovar os dentes ao levantar, após as refei ções e antes de dormir (2a , p. 252), ler somente com boa iluminação (2a , p. 252) não merecem nenhum desenvolvimento ou explicação, enquanto os autores julgam importante justificar: Tomar cuidado ao subir em árvores. 0 s gal hos podem quebrar, ou, ainda, mencionar Tomar cuidado para não tropeçar em objetos colocados no chão. (1ạ, p. 253). 0 utra demonstração do quanto é arcaico este tipo de enfoque pode ser verificada no livro da 1 a série onde (a título de exercício da nova habilidade de escrita ?) os autores as apresentam com a recomendação: copie no caderno 0 que precisamos fazer para ter boa saúde ou evitar acidentes.. (1a, p. 252, 253 e 255). 
O utro problema gerado pela utilização de regras não explicadas e em grande número, como vimos acima, é a confusão que elas podem gerar ao serem repetidas, tentando abranger situações mais amplas. U m exemplo são as recomendações a respeito da água própria para o consumo humano ao longo das quatro séries. $\mathrm{Na} 1^{\underline{a}}$ encontramos: Beber água pura, filtrada ou fervida; na 2 a é recomendado: Beber água filtrada. $\mathrm{N}$ ão beber água de rios; na 3a a regra é: somente beber água tratada com cloro ou filtrada e bem fervida, e na 4a série encontramos: beber água filtrada ou fervida e tomar água tratada e fervida. Seria muito mais proveitoso se, ao longo dos anos, os autores desenvolvessem o conceito de que a água pode conter substâncias impróprias à saúde e a necessidade indispensável que, mesmo advinda da estação de tratamento de água, quando isto ocorre, ela seja tratada novamente em casa antes de ser bebida (este processo caseiro pode consistir em filtros eficientes, fervura ou, ainda, aplicação de substâncias bactericidas como cloro ou água sanitária).

\section{- Coleção Aquarela (CA)}

Em termos de conteúdos apresentados, a Coleção Aquarela é menos densa se comparada à Integrando o A prender. N a CA, os Programas de Saúde compõem-se dos temas alimentação, regras de higiene, problemas com o lixo, tratamento de água e esgotos, que aparecem em todos os volumes da coleção. Os acidentes são tratados na 1 à série (p. 252) e na 3 a (p. 352), os primeiros socorros na 3a (p. 351), as doenças contagiosas e as vacinas só aparecem na $2^{\underline{a}}$ (p. 286) e as verminoses somente na $3^{a}$ ( (p. 349 e 350$)$.

Poluição é um conteúdo com abordagem de saúde que aparece em destaque dentro dos capítulos de ciências (1 $1 \stackrel{a}{a}$, p. 237, 3ạ, p. 313 e 321 e 4ạ, p. 428). Ainda integrantes do conteúdo de ciências são aqueles sobre animais que causam prejuízos ao homem (presente nas quatro séries), animais domésticos e a referência de que é necessário vaciná-los (1aㅡ e 2aa).

Também na CA verificamos a falta de conceituação dos conteúdos propostos. Saúde, por exemplo, é título de capítulo em todos os volumes, mas, da maneira como são apresentados e desenvolvidos os conteúdos relativos ao tema, torna-se difícil a síntese ou elaboração de algo mais consistente do que simples regras. 0 utros conteúdos não conceituados são raiva (1a, p. 223), desnutrição ( 3 ạ, p. 344 e 4ạ , p. 447) e tratamento da água (3â, p. 348 e 4a , p. 313). As definições, ao contrário, são abundantes e geralmente explici-

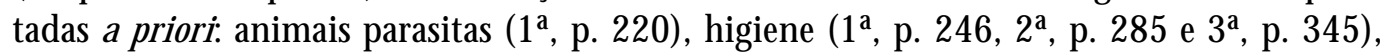
lixo (1a, p. 250 e 2a $2^{a}$, p. 287), doenças contagiosas ( $2^{a}$, p. 286), saneamento (3a- p. 348), alimentos (4a, p. 446) dentre outras.

No que diz respeito ao desenvolvimento de conceitos e definições, a CA deixa muito a desejar. $\mathrm{N}$ a maioria das vezes esse desenvolvimento é insuficiente; por exemplo, quando 0 autor menciona que os animais parasitas ( 1 a , p. 220 e 3a, p. 349) vivem dentro do corpo de outros seres, ele esquece dos ectoparasitas e da explicação do fenômeno do parasitismo, que é fundamental para a compreensão não só das verminoses, como das demais doenças infecciosas. $0 \mathrm{~s}$ alimentos são apresentados, em todas as séries, segundo sua classificação, seja de origem (1 1 a, p. 242 e 243 e 2ạ, p. 282), seja de componentes 
nutricionais ( $3 \stackrel{a}{a}$, p. 342 e 343 e 4ạ , p. 446). 0 corpo humano, na 2aㅗ série, é alvo de uma descrição anatômica paupérrima (p. 280). Sumárias, também, são as abordagens das verminoses na 3ạ (p. 349), da poluição e do tratamento da água na 4ạ (p. 425 e 428).

Tal como se verifica na coleção IA, muitas vezes o que se apresenta de um conteúdo são regras sem explicação ou qualquer fundamentação que permita sua compreensão, como se faz ao tratar de higiene (1 $1^{\mathrm{a}}, 2^{\mathrm{a}}$ e $3^{\mathrm{a}}$ ), de acidentes (1 $1^{\mathrm{a}}$ e $3^{\mathrm{a}}$ ) e de alimentação ( $2^{\mathrm{a}}$, $3^{\mathrm{a}}$ e $4^{\mathrm{a}}$ ), totalizando nesta coleção 92 regras.

É importante assinalar um conceito muito bem desenvolvido, no volume da 3 a série, sob o título Para você saber, p. 314. Trata-se de um texto sobre água poluída e contaminada, que, inclusive, demonstra a inutilidade das definições simplistas dadas nos outros volumes. M uito interessante também é a apresentação, na $2^{a}$ série (p. 278, ainda sob o título Para você saber), de um texto mencionando que nem todas as crianças, no Brasil e em outros países em desenvolvimento, têm chance de desenvolver-se adequadamente, 0 que é o tema do capítulo. A inclusão deste pequeno texto e de uma adaptação da D eclaração dos Direitos da Criança, que o segue, pedem a exploração das desigualdades sociais e de suas implicações nos problemas de saúde e de doença. Pena que este tipo de conteúdo esteja presente apenas no volume 2 da CA.

\section{- Coleção aprender com alegria (AA)}

N ovamente constatamos nesta obra a ausência de conceituação de alguns temas essenciais como saúde, nutrição e doenças. Há um bom número de conceitos implícitos, como éo caso dos alimentos (1 1 a e $4^{\underline{a}}$ séries), animais que causam prejuízo (1aㅡ 2aa e 3 a séries), embora seu desenvolvimento deixe a desejar. Somado ao fato de o livro dedicar poucas páginas aos Programas de Saúde, ou mesmo por isso, o professor interessado em resultados satisfatórios terá muito o que fazer.

A higiene, seja pessoal, doméstica, alimentar, social ou mental, é sempre apresentada sob a forma de regras sem fundamentação, perfazendo um total de 66 . A coleção AA atinge 96 instruções se somadas àquelas para cuidar da nossa saúde e segurança (1ä, p. 192), para preven ção das doenças contagi osas ( $2^{a}$,, p. 175), para evitar as verminoses e acidentes. ( 3 a , p. 208) e, novamente, para evitar as verminoses (4⿳a, p. 303). O s alimentos, a exemplo do que ocorre nas coleções IA e CA, são apresentados, classificados e nada mais. Insuficiente, por falta de fundamentação, é o desenvolvimento, no volume 2, dos termos: da poluição do ar (p. 163), dos cuidados com os animais domésticos e com os órgãos dos sentidos (p.171 e 173); no volume 3 , de animais parasitas (p. 203), desnutrição (p. 206), verminoses e acidentes (p. 208); de higiene alimentar (p. 296), lixo e esgoto (p. 299), no volume 4.

Identificamos alguns conteúdos com desenvolvimento insuficiente, devido a incorreções ou definições mal feitas. C omo na coleção IA, no capítulo sobre água poluída e contaminada (2ª p. p. 164, 3ạ, p. 190 e 4ạ , p. 282). Ali se usa uma definiç̧ão inútil de água pura, potável, poluída e contaminada. A página 164, do livro destinado à 2a série, exemplifica a confusão conceitual gerada ao explicar coisas que seriam simples, se bem fundamentadas. A água clorada é potável, mas pode ter o cheiro da substância; a água pode, por exemplo, também ser contaminada por metais pesados; pode haver uma água poluída que não contenha sujeiras 
aparentes, não seja turva e nem tenha cheiro ou sabor desagradáveis. A água não contaminada ou poluída dispensa qualquer tratamento para ser potável.

\section{Explicação dos termos desconhecidos}

$N$ a coleção IA, a utilização dos termos desconhecidos, em alguns casos deixa a desejar. Problemas com relação a este item são encontrados no volume da 1ª série (p. 254), no conteúdo sobre vacinas (com uma quantidade enorme de termos sem nenhuma explicação: vacinas, intradérmica, dose, reforço, poliomielite); o mesmo problema surge, novamente na $2^{a}$ ( $p$.

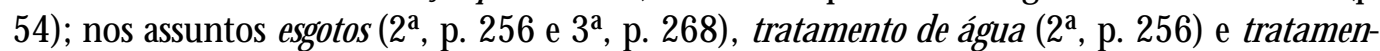
to de esgotos (4⿳亠丷厂巾, p. 314).

$\mathrm{Na}$ CA, notamos uma preocupação maior em explicar (o que nem sempre é alcançado) o vocabulário técnico utilizado, geralmente em notas de rodapé. Contudo, microscópio ( 2 a p. 286), vias respiratórias e vitamina B 1 (3a , p. 322 e 339) são termos novos que aparecem sem definição ou explicação. H á explicações e definições tautológicas do tipo: os alimentos reguladores ajudam a regular o funcionamento do organismo, os alimentos energéticos dão energia... (4ạ, p. 446).

$\mathrm{N}$ a coleção $\mathrm{AA}$, verificamos muitos termos técnicos sem uma adequada explicação ou sem nenhuma explicação. 0 ato de vacinar e 0 termo vacina são apenas mencionados no volume da 1 à série (p. 188). Bronquite, asma ealergia são termos que 0 autor julgou desnecessário explicar às crianças de 2 a série (p. 162), da mesma forma quando se refere a vermes e micróbios (p. 164). Também sem qualquer comentário explicativo encontram-se os termos água contaminada (3a , p. 208), raiva e fratura (3a , p. 209), produtos tóxicos e lençóis subterrâneos (4ạs, p. 283). A exemplo da CA, na coleção AA encontramos uma explicação tautológica sobre os alimentos energéticos (4⿳亠丷, p. 294).

\section{Correção científica}

\section{- Coleção Integrando 0 aprender (IA)}

Como vimos anteriormente, a coleção IA não apresenta os conceitos, limitandose a prescrições, conhecimentos factuais e episódicos. D iante disso, uma das opções do professor seria utilizar o livro como um dicionário ou enciclopédia. Para tanto, seria necessária a correção científica de muitos conteúdos. São abundantes nos quatro volumes afirmações incorretas que vão de leves para que os esgotos não cheguem di retamente aos rios e mares, devem ser construídas estações de tratamento de esgotos (2ª p. 256), ou, ainda, al guns invertebrados, como vermes e parasitas, vivem dentro de outros animais ( 2 a, p. 243) a absurdos como 0 conceito de animais úteis e nocivos ao homem (1a e $2^{2}$ a séries), denunciando a idéia dos autores de que a natureza existe para servir ao homem e a afirmação. $\mathrm{Na}$ 3 3 a série esta idéia é assim desenvolvida: G rande parte dos insetos são nocivos. Eles transmitem doenças, prejudicam as plantações e suas picadas são venenosas (p. 263). N ote-se que além do conceito útil/nocivo indesejado, 0 autor desconhece inteiramente que a classe Insecta tem mais de um milhão de espécies descritas. 
O utros exemplos de um conteúdo apresentado de maneira errônea: a verminose se transmite através dos ovos dos vermes (3ạa, p. 269); ainda: essas doenças são transmiti das por seres vivos muito pequenos chamados vírus, bactérias e protozoários, outras doenças são transmitidas por parasitas mai ores, que são os vermes (4ạ, p. 315), ou essas doenças são tran smitidas por seres vivos muito pequenos, chamados micróbios (2a, p. 253). Tais exemplos denunciam a ignorância dos autores sobre a diferença entre agente etiológico e formas de transmissão.

Também são graves as incorreções cometidas pela má explicação ou omissão de fatores importantes para a compreensão de determinados conceitos. U m exemplo típico é o capítulo referente à transmissão das doenças ( $2^{a}$ série, p. 253). Ali se diz que a doença pode ser transmitida por contágio direto (aperto de mão, tosse, espirro, etc.) ou indireto (copos, lenços, etc. que usamos depois de terem sido utilizados por pessoas doentes). 0 texto dá exemplo de doenças contagiosas (gripe, sarampo, caxumba, tuberculose, varicela), diz que podemos evitar essas doenças se tivermos os cuidados de tomar todas as vacinas, evitar o contato com pessoas doentes e ter uma alimentação bem saudável. Com esse texto, conclui-se que a forma de contágio (o correto seria usar transmissão) é a mesma para todas as doenças. $N$ ão é de estranhar, pois, o preconceito e a discriminação demonstrados com relação aos aidéticos, portadores de hanseníase, síndrome de D own, epilepsia, entre outros, pois, de acordo com o raciocínio acima, são doentes e precisam ser evitados.

Neste capítulo ignora-se a existência dos animais domésticos e sua importância como reservatórios e transmissores de zoonoses. Aliás, em toda a coleção IA, a raiva é citada em um texto de três linhas, uma única vez, no capítulo destinado ao estudo dos animais, onde se mencionam as características dos animais domésticos e a necessidade de vaciná-los (2ª série, p. 244). Com relação à transmissão, tampouco os autores da coleção IA se referem à existência de vetores, como os mosquitos, eà forma de como participam na dinâmica de uma enfermidade transmissível como o dengue, na época da publicação, já um problema de saúde pública importantíssimo no Estado do Rio de Janeiro.

0 missão de informação, deturpando sua correção, é encontrada também nos conteúdos relativos ao tratamento da água. 0 fato de a água passar por uma estação de tratamento (2a, p. 256 e 4⿳亠丷⿵冂丶 p. 313) necessariamente não a qualifica para consumo humano em todos os pontos da rede de distribuição, pois entre a estação e a torneira da cozinha, a água está sujeita à contaminação nos encanamentos públicos, na rede e nos reservatórios domésticos. Infelizmente esta explicação está ausente e, por isso, talvez o conceito seja incompreendido, quando na 3 a série (p. 268) os autores, ao contrário do que fazem nos outros volumes, mencionam que para torná-la [a água] livre de impurezas, exis tem, nas cidades, estações de tratamento de água. M esmo assim, devemos ferver ou filtrar a água antes de bebêla.

Erro grave é cometido, também, no conteúdo de primeiros socorros ( 3 a série, $p$. 272 e 4a , p. 318), ao instruir o uso não qualificado de pomadas para aliviar a dor, no caso de queimaduras, ou, ainda, recomendar que se provoque 0 vômito na pessoa envenenada, desconhecendo ser este procedimento indicado apenas no caso de envenenamento com produtos não-corrosivos. 0 missão grave neste tema é não mencionar, em nenhum volume, que uma das ações mais importantes, no caso de acidentes, é procurar auxílio especializado o mais rápido possível. Por outro lado, situações de acidentes simples e corriqueiros na 
infância não são exploradas. Em nenhum momento, ao longo da coleção IA, são apresentados conhecimentos que permitam a compreensão da importância da assepsia imediata de cortes e arranhões, por menores e mais superficiais que sejam, para evitar um possível desenvolvimento do bacilo do tétano. Ao contrário, na 4a série (p. 318), os autores recomendam: se o ferimento for muito profundo, a pessoa deverá ir ao hospital para suturar, isto é, costurar o local, e tomar a vacina anti-tetânica.

\section{- Coleção Aquarela (CA)}

$\mathrm{N}$ a presente obra também são constantes os absurdos de incorreção científica. M erece destaque, no volume da 1a série (p. 228), a idéia de que os ratos, as moscas e os mosquitos gostam de sujeira e transmitem doenças. Ao coletivizar o que é particular e minoria dentre as centenas ou milhares de espécies de ratos, moscas e mosquitos, o livro induz a uma estigmatização negativa desses animais, pondo por terra a feliz consideração de al gumas linhas acima, quando 0 autor afirma que Todos os animais são importantes na natureza. Estas associações errôneas provocam contradições importantes, por exemplo, quando de campanhas como a de combate ao Aedes, mosquito transmissor da dengue e da febre amarela, pois as pessoas têm dificuldade em aceitar o fato de que este vetor só se cria em coleções de água limpa. Como fazer com que a criança, que conhece ou tem camundongos brancos ou hamsters em casa, convença-se do fato de que esses animais podem tornar-se reservatórios de zoonoses, se ela os vê, ao contrário do livro, tão graciosos e asseados? Como não considerar a importância dos mesmos ratos como animais de laboratório?

Erro grave, presente nos volumes 1, 2 e 3, é a sinonimização do alimento com energia. Deslize de correção é cometido, também, ao comentar sobre os produtos alimentares industrializados (2a , p. 283). N ovamente, expondo a questão sem fundamentação, ao autor resta apresentá-la de maneira dogmática e equivocada. O s produtos químicos que podem provocar doenças não estão necessária e obrigatoriamente presentes nos alimentos industrializados. Assim como não são inócuos certos alimentos frescos e sucos naturais. No volume 4 (p. 447), este raciocínio errôneo volta a aparecer na recomendação Entre um refrigerante e um suco natural, dê preferência ao suco. Em tempos do cólera, mais segura é a opção pelo refrigerante.

O utra incorreção grave em uma abordagem de saúde e acidentes é encontrada no volume 3 (p. 339). Ao dizer que $\mathrm{Na}$ cidade de São Paulo, existe um local para atendimento de casos de pessoas picadas por animais venenosos. É o Instituto Butantã, 0 autor deixa de instruir sobre o procedimento correto no caso de pessoas vitimadas por animais peçonhentos, que é 0 encaminhamento imediato a um hospital de emergência, pronto socorro, posto médico ou qualquer outro local que disponha do soro específico. Além disso, tal texto não menciona outros institutos brasileiros como o Vital Brazil, em Niterói e o Ezequiel Dias, em Belo $\mathrm{H}$ orizonte, entre outros, que também se destacam na produção de soros anti-ofídicos.

\section{- Coleção Aprender com alegria (AA)}

Ao longo dos volumes não há a troca, como verificada nas coleções anteriores, do conceito de agente etiológico pelo de transmissor, a não ser uma vez, quando se afirma que $0 \mathrm{~s}$ vermes transmitem doenças que podem causar até a morte. (2ä, p. 164). 
N ovamente se verifica o problema da generalização com relação a uma determinada espécie de animal que pode causar prejuízo ao homem (2ª , p. 170 e 3a teúdos relativos às doenças contagiosas o mesmo comentário referido anteriormente é válido para esta coleção, que nos volumes 2 (p. 204) e 4 (p. 300) estigmatiza as doenças pela incorreção do texto. Positiva no volume 4 (p. 300) é a seguinte inclusão, que não ocorre nas coleções IA e CA: 0 contágio indireto acontece também através de animais como pulgas, percevejos, mosquitos, moscas, ratos, etc. A lastimar o fato de neste texto não se considerar, primeiro, a espe cificidade de cada vetor com cada tipo de doença, o que pode gerar um temor infundado com relação aos animais e, segundo, o uso do termo contágio em lugar de transmi ssão.

É inadmissível a forma como se aborda a questão do tratamento de esgotos, constatando que Geralmente, os esgotos costumam ser jogados nos rios ou mar. Existem cidades onde 0 esgoto étratado em estações de tratamento, antes de ser jogado nos rios ou no mar (3ä, p. 207), sem enfatizar a importância capital do tratamento dos esgotos, como as autoras, aliás, o fazem nos outros volumes (2a, p. 176 e 4a, p. 299).

No volume 4 (p. 300), há dois erros em um quadro onde são apresentadas as vacinas que hoje... protegem nosso organi smo contra as doenças. 0 primeiro é a indicação da vacina contra a varíola, que desde 1979, dois anos após a ocorrência do último caso registrado no mundo, foi considerada erradicada pela O rganização M undial de Saúde e descontinuada a vacinação. 0 segundo é a inclusão da vacina anti-rábica, na mesma categoria da pólio ou tríplice, que são consideradas vacinas obrigatórias.

\section{Prérequisitos}

Nas três coleções analisadas, com relação aos prérequisitos, a maioria dos conteúdos apresentados ou não os requer ou os desenvolve anteriormente. Contudo, verificam-se algumas exceções.

$\mathrm{Na}$ coleção IA os conteúdos de vacinas (1aa p. 254, 2ª̣, p. 253 e 4⿳亠丷a , p. 315) não podem ser entendidos sem as noções básicas sobre imunidade. 0 mesmo se aplica a ciclos de al gumas verminoses intestinais. Estes requerem alguns conhecimentos de anatomia e fisiologia para a compreensão de que um ovo de Ascaris, ao ser ingerido junto com o alimento, atravessa a parede intestinal já como larva, ganha a circulação sangüínea, atinge o coração e os pulmões, migra até a traquéia, atinge a faringe, onde é deglutido, e volta novamente ao intestino, para aí se desenvolver como verme adulto.

$\mathrm{Na}$ CA, o problema diz respeito ao conteúdo referente a verminoses, apresentado na 3a série (p. 350). Apesar de a ênfase não recair nos ciclos, mas na sintomatologia, sente-se falta do conteúdo relativo à dinâmica e integração dos sistemas no corpo humano (apresentado sob enfoque anatômico no volume 4) e do conceito de parasitismo.

Já na coleção $A A$, identificamos falta de desenvolvimento de conceitos anteriores a apresentação de conteúdos como animais domésticos (2ạ, p.171), quando falta o conceito de transmissão, e na apresentação das verminoses ( 3 a e 4 a série), que requer um mínimo de conhecimento da dinâmica de funcionamento do corpo humano (na 4a série 0 enfoque do corpo humano é puramente anatômico e descritivo). No volume 4 da coleção AA, a compreensão das vacinas não se torna possível pela falta da apresentação simplificada do que seja imunidade. 


\section{ANÁLISE DO CONTEÚDO DE "SAÚDE" EM LIVROSDIDÁTICOS}

\section{Adequação à idade mínima}

Com relação a este item, as três coleções, na maioria dos conteúdos abordados apresentaram-se relativamente satisfatórias. N ovamente há algumas exceções que podem ser bastante perigosas.

$\mathrm{N}$ a coleção IA a forma de abordagem do conteúdo de vacinas na 1a série (p. 254) é total mente inadequada para este nível. 0 mesmo vale para aquela relativa a primeiros socorros (3a p. 272 e 4 a p. 318-319), sugerindo alguns procedimentos que requerem habilidades não condizentes com a idade à qual se destinam os volumes. Por outro lado, os conteúdos são incompletos e incorretos, se os quisermos tomar como manual especializado.

$\mathrm{Na}$ CA também existem problemas relativos aos conteúdos de primeiros socorros na 3a série que, como na coleção IA, exigem habilidades geralmente inexistentes nesta faixa etária. Há inadequação no trecho: Ele [0 Instituto Butantã] recomenda que nós capturemos as cobras para enviá-las ao Instituto (3a- p. 339); obviamente trata-se de instrução perigosa quando dirigida a crianças.

\section{Adequação à realidade geográfica}

Com relação a este critério, todas as três coleções mostraram-se adequadas.

\section{Adequação à realidade econômica}

As coleções não apresentam o mesmo desempenho do item anterior quando analisadas sob o critério da adequação à realidade econômica. Todas as três coleções, ao desenvolverem 0 tema alimentos pressupõem que 0 leitor tenha acesso aos alimentos de que necessite ou que escolha. $N$ este caso, mais proveitoso seria propor textos e atividades que estimulassem a exploração do cotidiano alimentar dos alunos, os acertos, as mudanças desejáveis e as carências verificadas. $\mathrm{N}$ o que diz respeito à higiene alimentar e pessoal, o modo como os textos trazem as recomendações, subentende a presença de uma cozinha com seus utensílios, de uma pia com água encanada ou corrente para a lavagem dos alimentos, de um banheiro provido de vaso sanitário, onde devem ser feitas as necessidades, de uma pia, onde as mãos são lavadas e os dentes são escovados e de um chuveiro para 0 banho diário. 0 fato de não haver exploração do que o aluno dispõe e do que lhe falta para poder ter a higiene descrita no livro, pode gerar a idéia de algo inatingível e irreal, em algumas situações de carência. $\mathrm{N}$ a coleção IA, quando os autores abordam os acidentes, omitem os perigos das janelas dos edifícios, das linhas de trem, dos envenenamentos por medicamentos e produtos sanitários, das queimaduras sofridas dentro de casa. 0 perigo das vias públicas e do trânsito são lembrados de uma maneira absolutamente inócua: respeitar os sinais de trânsito ao atravessar a rua e não correr atrás da bola no meio da rua, sem ol har para os dois lados (3a , p. 272). Em nenhum dos 12 volumes analisados é mencionado o problema da violência que responde por $46,05 \%$ dos óbitos na faixa etária de 5 a 14 anos, constituindo-se na maior causa de mortalidade nesta faixa etária (M inayo et al., 1992), nem questões relacionadas ao fumo, às drogas ou aos entorpecentes. 


\section{Enfoque sanitário}

Todas as coleções privilegiam um enfoque sanitário preventivo, à exceção (óbvia) dos conteúdos relativos aos primeiros socorros.

$\mathrm{Na}$ CA, seria interessante desenvolver o conceito de soro que é apenas uma citação de passagem (3a, p. 339).

\section{Ações requeridas / recomendadas}

As três coleções são extremamente semel hantes também com relação a este critério de análise, apresentando basicamente ações individuais como responsáveis pela manutenção ou recuperação da saúde. Seria conveniente dosar mais adequadamente o que diz respeito ao indivíduo e o que precisa ser feito a nível coletivo.

Apenas nos temas que enfocam a poluição, nas coleções IA e CA, encontramos referências a ações de cunho coletivo, muito embora exploradas bastante superficialmente.

$\mathrm{Na}$ coleção $\mathrm{AA}$, além dos capítulos referentes à poluição, naqueles que abordam 0 saneamento há um enfoque de col etividade. Este, porém, como um bem coletivo: 0 ar, as estações de tratamento de água e esgoto. $N$ ão há a preocupação de referência que al gumas ações de saúde, embora individuais, só têm sentido se coletivizadas. Um desses exemplos é 0 controle de Aedes aegypti, quando pouco adiantam ações isoladas. 0 utro, são as campanhas de vacinação contra a poliomielite ou o sarampo que, para serem eficazes no bloqueio da transmissão, necessitam atingir mais de $95 \%$ da população em um prazo muito curto.

\section{Influência/relação com o meio ambiente}

N enhuma das três coleções diferenciam-se com relação a este critério: é regra a não consideração do meio ambiente nas condições de saúde e de doença. Ao invés de apresentálas como um estado dinâmico, dependente das interações que o homem mantém com os meios biótico, físico e social e das relações existentes em seu próprio corpo, os autores prefe rem enfatizar a doença unicamente como uma entidade contagiosa e caracterizam a saúde como a ausência de doença ou acidentes.

$\mathrm{Na} \mathrm{CA}$, por exemplo, os conteúdos analisados só abordam a influência do meio ambiente, quando tratam do problema da poluição do ar e da água. No restante, tal relação está ausente. Q uando trata da origem dos alimentos, por exemplo, o leite é representado em sua embalagem de supermercado (1a, p. 242, 3a, p. 342 e 4a, p. 446), o mesmo

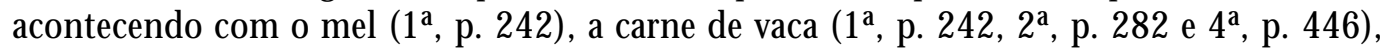
0 arroz (3a, p. 342), assim como com todas as frutas e verduras apresentadas nos quatro volumes. Tal abordagem gera o descrito por M achado (1991): Só que galinha, para a criança de cidade grande, é alguma coisa que é sempre congelada, enrolada em plástico e produzida pelo supermercado. ... É o caso de uma criança que viu uma galinha viva e falou assim: 'O lha, mãe, a galinha está toda suja de pena.'

$\mathrm{N}$ a coleção $\mathrm{AA}$, notamos uma breve referência às relações saúde-ambiente quando as autoras apresentam a poluição do ar e da água (2å , p. 163 e 164 e 3ạ, p. 282). Ao 


\section{ANÁLISE DO CONTEÚDO DE “SAÚDE" EM LIVROS DIDÁTICOS}

tratarem de doenças como dengue, doença de Chagas, tétano e verminoses (4⿳亠口冋 série), 0 ambiente é apenas citado de passagem. $0 \mathrm{~s}$ alimentos são representados como os vemos no supermercado, tal qual na CA.

\section{Aprofundamento relativo à série anterior}

A coleção IA, com relação a complexidade gradativa dos conteúdos apresentados, deixa a desejar nos capítulos relativos a higiene, alimentação, vacinas e saneamento básico. N ão é raro encontrarmos nestes capítulos livros de 1 a ou 2 a série mais ricos que os de 3a e 4ạ.

Já na CA, 0 aprofundamento é feito através da apresentação de alguns novos conteúdos em cada volume. Para aqueles já abordados em volumes anteriores, o conteúdo e a complexidade são praticamente os mesmos, inclusive com a repetição dos mesmos textos:

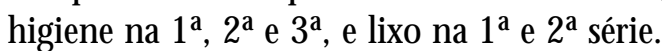

D a mesma forma, na coleção $A A, 0$ aprofundamento com relação à série anterior é feito, na maioria das vezes, através da introdução de novos conteúdos. Em poucos casos, podemos constatá-lo a partir do aumento da complexidade de um mesmo conteúdo, como por exemplo no volume 3 (p. 205) que aborda a constituição molecular dos alimentos, quando no volume 2 foi considerada a origem dos mesmos. $\mathrm{Na}$ 4 a série, apresenta-se a função dos nutrientes no corpo humano.

\section{Tipos de atividades propostas}

Em todos os volumes da coleção IA, as atividades propostas aos al unos reduzemse, quase que exclusivamente, a exercícios onde 0 aluno simplesmente deve identificar, no texto anterior, o trecho relativo à questão que lhe é proposta e completar a resposta com a frase do autor. U ma variação deste tipo de exercício pede ao aluno que complete a palavra ausente na frase do exercício, repetindo 0 texto. Do total de 184 atividades, nos quatro volumes da coleção, 133 são deste tipo - cópia; 33 são de análise, exigindo que 0 aluno responda a questão, sem apresentar a solução no texto. Em 12 ocasiões, o livro propõe exercícios de resposta aberta (escreva como você cuida de sua saúde [1ạ, p. 252], quais são os seus divertimentos? [4a, p. 312], escreva o nome dos alimentos que você costuma comer [ $1 \stackrel{a}{\text { a }}$ p. 251]). As atividades extra-livro didático são propostas seis vezes ao longo da coleção (Faça uma pesquisa completa e organize no caderno um trabalho com o título 'o tratamento de água em minha cidade. [4a , p. 314]). Por duas vezes, entretanto, estas atividades resumem-se a pergunte a sua mãe e responda: quais as vacinas que você já tomou? [2ạ, p. 254] ou, ainda, pergunte a seus pais as vacinas que vocêjá tomou e escreva no caderno [1a, p. 254]. Esta abordagem traz problemas ao pressupor a presença da mãe, além de desestimular a iniciativa do aluno. 0 comportamento positivo a estimular é que o próprio indivíduo se torne responsável pela sua saúde, exigindo (da mãe, do responsável ou da autoridade competente) os meios de preservá-la ou recuperá-la. Bastaria que o autor indagasse simplesmente ' $Q$ uais as vacinas que você já tomou?' 
$\mathrm{Na}$ CA também predominam exercícios do tipo cópia; de 202 atividades propostas no livro, 133 são deste tipo. Verificamos, entretanto, em relação à coleção anterior, um peque no aumento no número de exercícios que requerem análise dos textos apresentados (40 exercícios), exercícios do tipo resposta aberta (20) e atividades extra-livro didático (8). H á um exercício de resolução de problema.

N os volumes da coleção AA, do total de 183 atividades propostas, embora haja predomínio dos exercícios de simples cópia do texto apresentado (88) e a análise represente 36 exercícios, encontramos um maior número dos outros tipos de atividades: 47 permitem ou requerem uma resposta aberta e as atividades extra-livro didático são solicitadas 12 vezes. D entre estas últimas, cabe elogiar as propostas presentes no volume 2 (p. 164 e 170), onde as autoras sugerem, sem direcionar, atividades de pesquisa sobre água contaminada e verminoses e sobre os prejuízos que al guns animais podem causar ao homem. Propõe-se que, para realizar o trabal ho, 0 aluno pesquise em casa, na biblioteca e nos postos de saúde ( $p .164$ ) e em conversas com os pais e professores (p. 170). No volume destinado à 4a série, ao contrário das coleções anteriores, as autoras dizem: procure saber os nomes das vacinas que vocêjá tomou para se defender das doenças.. (p. 301). Também no volume 4 encontra-se a proposição de; as demais são de execução individual.

\section{Forma de execução das atividades propostas}

As três coleções assemelham-se profundamente quando da aplicação deste critério. Em todas elas, a forma de realização das atividades propostas é quase que exclusivamente individual (exceção à coleção $\mathrm{AA}$, que no volume da 4ạ série propõe duas atividades em grupo: p. 303 e 304). Assim, perde-se a oportunidade, mesmo nas atividades que não são de cópia do texto, de realizar debates e discussões entre membros de um pequeno grupo ou entre a classe. Tal postura é coerente com a ênfase dada nas ações individuais para 0 alcance e a manuten ção da boa saúde. Além disso, os tipos de atividades não se tornam mais complexos conforme 0 avanço da escolaridade.

\section{Ilustrações}

\section{Coleção Integrando o aprender (IA)}

As ilustrações são desenhos coloridos, não havendo fotografias.

Existem fal has nas ilustrações técnicas. $H$ á casos de desenhos errados, como na página 270, 3ạ série, e página 316, 4a série, onde um caramujo terrestre, que pode ser encontrado em qualquer jardim, participa do ciclo da esquistossomose, criando um temor infundado de que os moluscos terrestres são vetores desta doença, fato já verificado por alguns autores (Schall, 1987 e M achado, 1991).

0 utras vezes são as legendas que não condizem com o desenhado. N a página 317 do volume da 4a série vêem-se dois adultos de Ascaris lumbricoides, mas a legenda diz tratarse de larvas. N a página 270, 3ạ série, um casal de esquistossomos em acasalamento é legendado como esquistossomo. 
0 mais comum, entretanto, é a falta de indicação de escala nos desenhos. M osquitos são mostrados do tamanho de ratos (1a , p. 243 e 2a, p. 245), os miracídeos e as cercárias têm tamanho de sardinhas, senão maiores (3ạ, p. 270, e 4aa p. 316). 0 vos de Ascaris, de Ancylostoma e de Taenia tornam-se gigantescos, quando comparados com os seres humanos que os acompanham nas ilustrações (3a-, p. 269 e 270, e 4a , p. 317). Ao espe cialista pode parecer pouco provável que uma criança, observando um ambiente aquático, procure ali cercárias, que, pelos desenhos, imagi na ser do tamanho de peixinhos, mas tal fato ocorre com freqüência (Schall, 1987). N a impossibilidade da utilização de exemplos reais, é possível desenhá-los em escala junto a objetos mais conhecidos como, por exemplo, uma cabeça de alfinete. Seres microscópicos podem, ainda, ser representados sob uma lente de aumento. D esenhos de organismos maiores devem incluir escala métrica ou outro referencial conhecido.

Em alguns casos, mesmo os desenhos não-técnicos, como a primeira ilustração, página 255, 1a série, reforçam erroneamente um texto já incompleto, quando mostra os sacos de lixo sendo depositados na calçada, ao alcance de cães. Pior é o desenho da página 253, 2ª série, no qual, para ilustrar doenças infecciosas, são desenhadas situações de transmissão dire ta e indireta, onde os personagens estão uniformizados, caracterizando um ambiente escolar. Seria importante esclarecer a necessidade do isolamento em alguns casos de doenças infecciosas, explicando quando e como há o perigo da transmissão.

\section{Coleção Aquarela (CA)}

Esta coleção apresenta fotografias e desenhos, ambos em cores.

As ilustrações tomam demasiado espaço no livro; muitas chegam a ocupar três quartos de página. Fica a impressão, pela disposição e tamanho desnecessário de certas ilustrações, de que foram ali colocadas para suprir a falta do texto escrito.

Ilustrações técnicas incorretas e de péssima qualidade são localizadas nas páginas 220 (1a) e 349 (3ㄹ) nas referências a parasitas e vermes, respectivamente. N os dois casos, falta escala: as lombrigas e ancilóstomos se parecem com minhocas (inclusive com segmentação aparente). H á o desenho de um ovo de Ascaris sem qualquer identificação, completamente desproporcional ao verme adulto colocado ao lado. N aquele legendado como esquistossomo, o que se vê é um casal desses vermes em cópula, igualmente ao que ocorre na coleção IA.

\section{Coleção Aprender com alegria (AA)}

$\mathrm{N}$ a presente coleção, como em IA, da mesma editora, as ilustrações são desenhos coloridos, coerentes com o texto que ilustram. $\mathrm{N}$ ão há fotografias.

Verifiquei, contudo, dois tipos de problemas. 0 primeiro diz respeito à má qualidade dos desenhos nos capítulos de alimentos e nutrição, desenhos esses que permitem dupla interpretação (1a, p. 190 e 3a , p. 205, respectivamente). 0 segundo, como nas coleções anteriores, refere-se à ausência de escala, o que causa uma confusão na identificação dos animais representados (2ª p. p. 169 e 170 e 4a, p. 301): Iombriga, tênia, escorpião e Aedes. Isto 
é mais sério do que, a princípio, se pode imaginar. 0 M inistério da Saúde, há alguns anos elaborou material informativo para subsidiar a campanha de controle de Aedes aegypti. Faziam parte dele cartazes de aproximadamente $50 \times 70 \mathrm{~cm}$ com o mosquito desenhado em quase toda a mancha. A Sucam, ao distribuir os cartazes pelas comunidades, ouviu dos moradores que naquele local não haveria problemas com o dengue ou a febre amarela, pois não havia tal mosquito: os pernilongos, comuns na região, eram bastante menores.

\section{Agradecimentos}

A Esther $M$ aria de $M$ agalhães Arantes, que orientou a dissertação de mestrado.

A Fernando D ias de Ávila Pires pelas discussões, sugestões e apoio que possibilitaram sua realização.

A M aria Sueli Parreira de Arruda, coordenadora do "Encontro de Pesquisadores em Educação para a Saúde - abordagem de temas de saúde no livro didático", por propiciar minha participação nesta reunião e pela troca de idéias aí realizada.

\section{Referências bibliográficas}

BELLU CI, M.E., CAVALCANTE, L. G. Integrando o aprender. 9. ed. São Paulo, Scipione, 1991.

M ACH AD O , A. N atureza e educação ambiental. In: EN CON TRO N ACIO N AL DE EDU CAÇAO AM BIENTAL, 1, Curitiba. Anais... Curitiba, 1991. p. 53-69.

M AROTE, D. Coleção aquarela. 3. ed. São Paulo, Ática, 1991.

M IN AYO, C. et al. Desigualdades sociais e meio ambiente. In: CONFERÊN CIA INTERNACIONAL DE MEIO AM BIENTE, DESEN VO LVIMENTO E SAÚDE, Rio de Janeiro. Carta da Saúde, Agenda Sanitária e Relatórios Finais. Rio de Janeiro, Fundação O swaldo C ruz, 1992. p. 14-24.

M O H R, A. A saúde na escola: análise de livros didáticos de 1aa a 4a séries. Cadernos de Pesquisa, V. 94, p. 50-57.

M O LIN A, O. Q uem engana quem: professor x livro didático. Campinas, Papirus, 1987.

PASSOS, L., FO N SECA, A., CH AVES, M . Aprender com alegria, 6. ed. São Paulo, Scipione, 1991.

SCH ALL, V.T. et al. Educação em saúde para alunos de primeiro grau: avaliação de material para ensino e profilaxia da esquistossomose. Revista de Saúde Pública, v. 21, n. 5, 1987. p. 387-404. 